\title{
Physiological determinants of race walking performance in female race walkers
}

\author{
T. Yoshida, PhD $^{1}$, M. Udo, MD ${ }^{1}$, K. Iwai, MS ${ }^{1}$, I. Muraoka, MS ${ }^{2}$, K. Tamaki, MS ${ }^{2}$, T. \\ Yamaguchi ${ }^{3}$ and $M$. Chida, MD $^{4}$
}

\author{
${ }^{1}$ Exercise Physiology Laboratory, Faculty of Health and Sport Sciences, Osaka University, Japan \\ ${ }^{2}$ Exercise Physiology Laboratory, Department of Human Sciences, Waseda University, Japan \\ ${ }^{3}$ Track and Field Laboratory, Department of Physical Education, Tokyo Women's College of Physical Education, \\ Japan \\ ${ }^{4}$ Division of Respiratory Physiology and Internal Medicine, Department of Medicine, Tokyo Medical and Dental \\ University, Japan
}

\begin{abstract}
The purpose of this study was to determine the relationship between race pace on a $5 \mathbf{~ k m}$ walking performance and velocity at the lactate threshold (V-LT), $\mathrm{VO}_{2}$ at the lactate threshold $\left(\mathrm{VO}_{2}-\mathrm{LT}\right)$, velocity at which blood lactate corresponded to $4 \mathrm{mM}$ level (V-OBLA), $\mathrm{VO}_{2}$ at which blood lactate corresponded to $4 \mathrm{mM}$ level $\left(\mathrm{VO}_{2}\right.$-OBLA), walking economy (steady state $\mathrm{VO}_{2}$ at a standard velocity) and maximal oxygen uptake ( $\left(\mathrm{VO}_{2} \mathrm{max}\right)$ in eight female race walkers.

A multiple stepwise linear regression analysis was employed to predict the race pace on a $5 \mathrm{~km}$ walking performance as dependent variable. Since V-OBLA was highly correlated to $5 \mathrm{~km}$ race walking performance $(r=0.94$, $P<0.001$ ), it was selected as the first predictor. When $\mathrm{VO}_{2}$ max was added to V-OBLA as the second predictor the predictive accuracy increased significantly, but multiple $R$ did not increase significantly by adding variables of walking economy or other parameters as independent variance.

As a result, the combination of $\mathrm{V}-\mathrm{OBLA}$ and $\mathrm{VO}_{2} \max$ as independent variables accounted for the greatest amount of total variance ( 97 per cent). It is suggested that blood lactate variable such as V-OBLA can account for a large portion of the variance in race pace on a $5 \mathrm{~km}$ walking performance.
\end{abstract}

Keywords: Lactate threshold, onset of blood lactate accumulation, race walking performance

\section{Introduction}

Numerous investigations have pointed out high correlations between distance running performance and blood lactate variables such as lactate threshold (LT) and/or onset of blood lactate accumulation (OBLA) ${ }^{1-6}$. Some data are available for physiological factors related to walking performance in male race walkers. Hagberg and Coyle pointed out that the velocity at lactate threshold (V-LT) is the best predictive factor for performance in race walkers and that submaximal walking economy appeared to be related more closely to performance in race walking than in running ${ }^{3}$.

Address for correspondence: Dr T. Yoshida, Exercise Physiology Laboratory, Faculty of Health and Sport Sciences, Osaka University, Toyonaka 560, Japan

(C) 1989 Butterworth \& Co (Publishers) Ltd 0306-3674/89/040250-05\$03.00
To date, no study of competitive female race walkers has been published.

The purpose of the present study was to evaluate the relationship between blood lactate variables, cardiovascular functions and race performance in female walkers.

\section{Methods}

Eight experienced female race walkers, including a 1987 World Cup Qualifier and a Japan record holder, served as subjects in the study. They gave informed consent to participate in the study. Their physical characteristics are listed in Table 1.

Laboratory data were collected two weeks before the athletes competed in a $5 \mathrm{~km}$ road race, which was contested on a flat course, officially arranged and certified by the Japanese Association of Track and Field. Finish time was recorded for each athlete as $5 \mathrm{~km}$ walking performance and its mean velocity is defined as race pace on a $5 \mathrm{~km}$ walking performance and is used for further statistical anaylses.

To determine the lactate-related variables, walking economy and $\mathrm{VO}_{2}$ max, a treadmill multi-progressive exercise test was performed. The test consisted of the initial walking velocity of $140 \mathrm{~m} \cdot \mathrm{min}^{-1}$ for $5 \mathrm{~min}$, and thereafter the treadmill velocity was increased by $10 \mathrm{~m} \cdot \mathrm{min}^{-1}$ every $5 \mathrm{~min}$. After reaching $\mathrm{V}-\mathrm{OBLA}$ (blood lactate concentration corresponding to $4 \mathrm{mM}$ ), treadmill velocity was increased until volitional exhaustion.

During the treadmill exercise test, the subjects breathed through a low resistance Rudolph valve \#2700. The expired gas was collected into a Douglas bag during the final minute of each treadmill velocity. The collected gas was immediately assessed for volume of ventilation $\left(V_{E}\right)$ by a dry gas meter which had been calibrated.

A portion of the collected gas was dried with $\mathrm{CaCl}_{2}$ and then analysed for $\mathrm{O}_{2}$ and $\mathrm{CO}_{2}$ concentrations by means of an oxygen analyser with a zirconium oxidase membrane and an infra-red carbon dioxide analyser (MG-360, Torey Engineering Ltd, Japan), respectively. 
Table 1. Physical characteristics of the subjects

\begin{tabular}{|c|c|c|c|c|c|c|}
\hline Subject & $\begin{array}{c}\text { Age } \\
\text { (yr) }\end{array}$ & $\begin{array}{l}\text { Height } \\
\text { (cm) }\end{array}$ & $\begin{array}{l}\text { Weight } \\
\text { (kg) }\end{array}$ & $\underset{\left(m l \cdot \mathrm{kg}^{-1} \cdot \min ^{-1}\right)}{\mathrm{VO}_{2} \max }$ & $\begin{array}{c}5 \mathrm{~km} \text { Walk } \\
\text { (performance) } \\
\text { (min:sec) }\end{array}$ & $\begin{array}{l}\text { ime } \\
\text { (race pace) } \\
\left(\mathrm{m} \cdot \mathrm{min}^{-1}\right)\end{array}$ \\
\hline $\begin{array}{l}1 \\
2 \\
3 \\
4 \\
5 \\
6 \\
7 \\
8\end{array}$ & $\begin{array}{l}20 \\
20 \\
23 \\
20 \\
20 \\
18 \\
19 \\
21\end{array}$ & $\begin{array}{l}162 \\
170 \\
158 \\
156 \\
165 \\
164 \\
164 \\
153\end{array}$ & $\begin{array}{l}48.9 \\
56.1 \\
50.0 \\
40.4 \\
59.4 \\
52.4 \\
52.4 \\
48.3\end{array}$ & $\begin{array}{l}51.9 \\
54.2 \\
50.5 \\
49.9 \\
46.9 \\
49.3 \\
49.4 \\
46.5\end{array}$ & $\begin{array}{l}23: 29 \\
24: 24 \\
24: 31 \\
25: 00 \\
26: 34 \\
27: 18 \\
29: 02 \\
29: 20\end{array}$ & $\begin{array}{l}212.9 \\
204.9 \\
203.9 \\
200.0 \\
188.2 \\
183.2 \\
172.2 \\
168.6\end{array}$ \\
\hline $\begin{array}{l}\text { Mean } \\
\pm S D\end{array}$ & $\begin{array}{r}20.1 \\
1.5\end{array}$ & $\begin{array}{r}161.5 \\
5.5\end{array}$ & $\begin{array}{r}51.0 \\
5.7\end{array}$ & $\begin{array}{r}49.8 \\
2.5\end{array}$ & $\begin{array}{r}26: 15 \\
2: 17\end{array}$ & $\begin{array}{r}191.7 \\
16.2\end{array}$ \\
\hline
\end{tabular}

These were calibrated against an air and a standard gas which had been calibrated by a micro-Sholander gas analyser.

Walking economy is defined as the steady state oxygen consumption for a standard treadmill velocity. In the present study, walking economy was determined from $\mathrm{VO}_{2}$ at treadmill velocity of $170 \mathrm{~m} \cdot \mathrm{min}^{-1}$.

To obtain the blood samples, a Teflon catheter was inserted into a dorsal hand vein. By using an electrical heating pad, arterialized-venous blood samples were taken at the time of 4.5 th min of each stage of treadmill walking velocity ${ }^{\top}$. Blood lactate $(\mathrm{HLa})$ was determined by lactate analyser with enzymatic electrode method (HEK-30L, Toyobo, Japan) within $1 \mathrm{~min}$ immediately after each blood sampling. This analyser was calibrated against standard lactate solutions.

The lactate threshold (LT) is defined as the point at which blood HLa begins to increase above the resting level $^{8}$. In other words, LT is the highest exercise intensity without any accumulation of lactate during the incremental exercise. Similarly, the walking velocity at LT (V-LT) is considered as the highest walking velocity without any accumulation of HLa in the blood. To identify the LT, a log-log transformation of lactatewalking velocity (or $\mathrm{VO}_{2}$ ) relationship was used according to the procedure described by Beaver et al. ${ }^{9}$. This transformation was also used to determine VOBLA and $\mathrm{VO}_{2}$-OBLA (Figure 1).

The data for $\mathrm{V}$-LT $\left(\mathrm{m} \cdot \mathrm{min}^{-1}\right), \mathrm{VO}_{2}-\mathrm{LT}\left(\mathrm{ml} \cdot \mathrm{kg}^{-1} \cdot \mathrm{min}^{1}\right)$, $\mathrm{V}-\mathrm{OBLA}\left(\mathrm{m} \cdot \mathrm{min}^{-1}\right), \mathrm{VO}_{2}-\mathrm{OBLA}\left(\mathrm{ml} \cdot \mathrm{kg}^{-1} \cdot \mathrm{min}^{-1}\right)$, walking economy $\left(\mathrm{ml} \cdot \mathrm{kg}^{-1} \cdot \mathrm{min}^{-1}\right)$, and $\mathrm{VO}_{2} \max$ $\left(\mathrm{ml} \cdot \mathrm{kg} \cdot \mathrm{min}^{-1}\right)$ were entered into a linear regression analysis (SAS STEPWISE). STEPWISE combines the best features of forward inclusion and backward elimination to determine the most important measures in predicting the dependent variable, which is race pace on a $5 \mathrm{~km}$ walking performance. The $P<0.05$ level of significance was selected for all correlations.

\section{Results}

Table 2 indicates selected descriptive data. In the present study, the subjects were fairly heterogeneous in terms of race walking performance; their mean velocity in $5 \mathrm{~km}$ walking ranged from $168.6-212.9 \mathrm{~m} \cdot \mathrm{min}^{1}$ with $16.2 \mathrm{~m} \cdot \mathrm{min}^{-1}$ of SD.

The simple correlations of the descriptive parameters shown in Table 2. These parameters as in- dependent variables with race pace on $5 \mathrm{~km}$ walking performance as dependent variable are illustrated in Figure 2.

Table 3 provides data from a STEPWISE multiple regression analysis, using the race pace on a $5 \mathrm{~km}$ walking performance as dependent variable. Since simple correlation of $\mathrm{V}$-OBLA is the highest with the race pace ( $r=0.94, P<0.001)$, it was selected as the first predictor. When $\mathrm{VO}_{2 \max }$ was added to $\mathrm{V}$-OBLA as the second predictor, the predictive accuracy increased significantly. However, multiple $\mathrm{R}$ did not increase significantly by adding variables of V-LT, walking economy or other parameters as independent variables. The combination of V-OBLA and $\mathrm{VO}_{2 \max }$ as independent variables accounted for the greatest amount of total variance (97 per cent).

A STEPWISE regression procedure was applied for dependent variable of race pace on a $5 \mathrm{~km}$ walking performance. The 0.150 significance level has been set for data entry into the model. A multiple regression equation for predicting the race pace as a $5 \mathrm{~km}$ walking performance was formulated using partial regression coefficients as follows:

$5 \mathrm{~km}$ race pace $\left(\mathrm{m} \cdot \mathrm{min}^{-1}\right) \|=0.813 \mathrm{~V}$ $\mathrm{OBLA}+2.193 \mathrm{VO}_{2} \mathrm{max}-60.401$

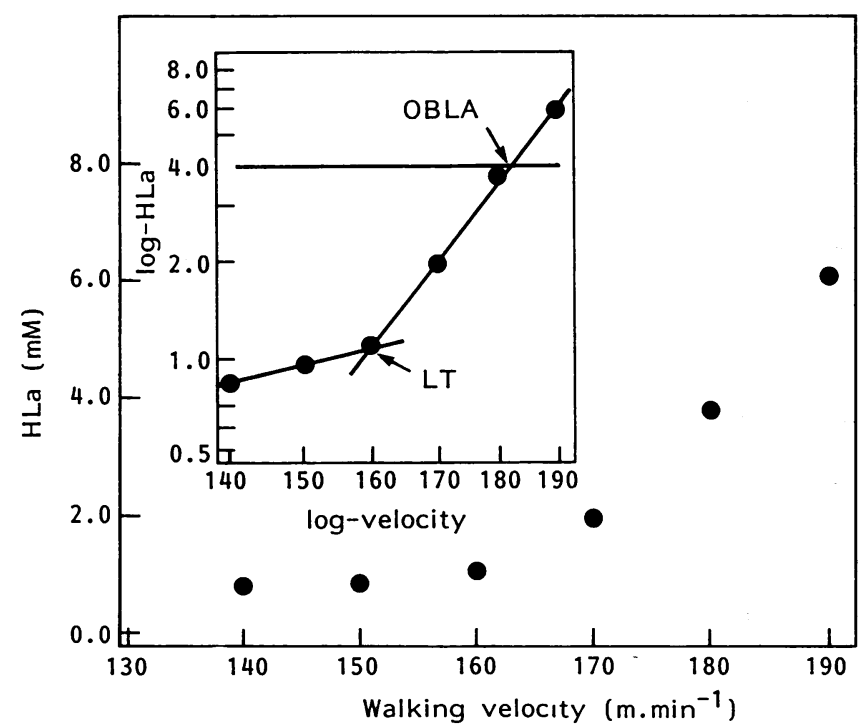

Figure 1. A. An example of blood lactate concentration (HLa) during progressive incremental treadmill walking $B$ : Its log-log transformation for detecting lactate threshold and OBLA 
Physiological assessment in race walking performance: T. Yoshida et al.

Table 2. The descriptive data obtained during submaximal treadmill exercise

\begin{tabular}{|c|c|c|c|c|c|}
\hline Subject & $V-L T^{a}$ & $\mathrm{VO}_{2}-L T^{b}$ & $V-O B L A^{a}$ & $\mathrm{VO}_{2}-\mathrm{OBL} A^{b}$ & Walking economy $^{b}$ \\
\hline $\begin{array}{l}1 \\
2 \\
3 \\
4 \\
6 \\
7 \\
8\end{array}$ & $\begin{array}{l}165 \\
150 \\
150 \\
160 \\
150 \\
140 \\
140\end{array}$ & $\begin{array}{l}35.5 \\
38.3 \\
33.7 \\
36.3 \\
37.4 \\
34.4 \\
31.0\end{array}$ & $\begin{array}{l}194.1 \\
182.5 \\
190.0 \\
180.9 \\
183.3 \\
157.1 \\
154.7\end{array}$ & $\begin{array}{l}4.5 \\
49.5 \\
44.6 \\
44.7 \\
44.7 \\
41.5 \\
42.9\end{array}$ & $\begin{array}{l}37.3 \\
46.3 \\
39.9 \\
41.0 \\
40.4 \\
44.8 \\
46.2\end{array}$ \\
\hline $\begin{array}{l}\text { Mean } \\
\pm S D\end{array}$ & $\begin{array}{r}149.4 \\
9.4\end{array}$ & $\begin{array}{r}35.4 \\
2.3\end{array}$ & $\begin{array}{r}175.7 \\
15.2\end{array}$ & $\begin{array}{r}44.4 \\
2.4\end{array}$ & $\begin{array}{r}42.9 \\
3.7\end{array}$ \\
\hline
\end{tabular}

a: $\mathrm{m} \cdot \mathrm{min}^{-1}$

$\mathrm{b}: \mathrm{ml} \cdot \mathrm{kg}^{-1} \cdot \mathrm{min}^{-1}$
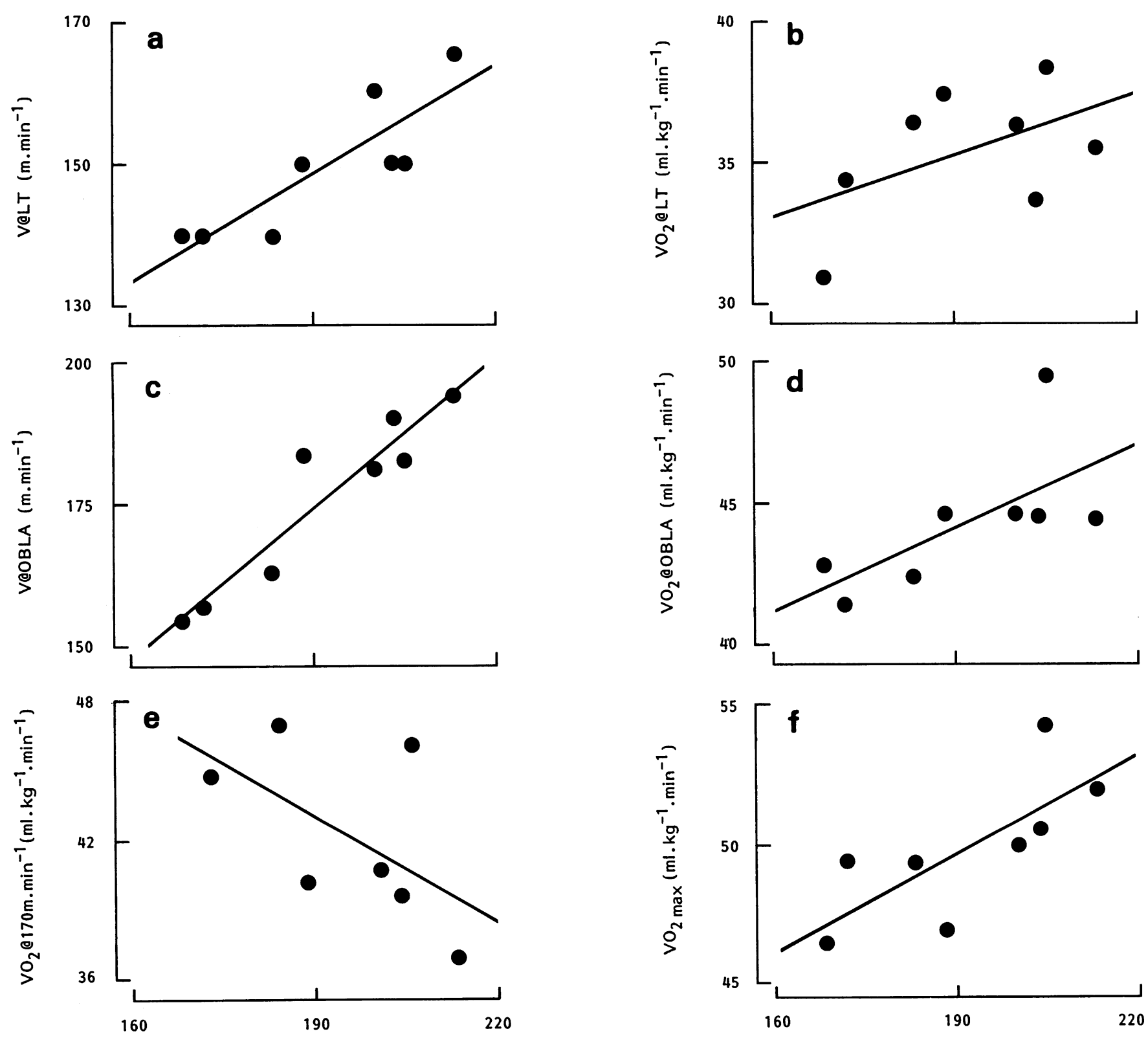

Figure 2. Relationship between the descriptive data obtained during the treadmill incremental exercise test and race pace on a $5 \mathrm{~km}$ walking performance $A$. walking velocity at $L T(V-L T), B . V_{2}$ at LT $\left(V^{2} O_{2}-L T\right), C$. walking velocity at OBLA $(V-O B L A), D: V_{2}$ at OBLA (VO2-OBLA), $\mathrm{E}: \mathrm{VO}_{2}$ at $170 \mathrm{~m} \cdot \mathrm{min}^{-1}$ as walking economy and $\mathrm{F}: \mathrm{VO}_{2 \max }$ 
Physiological assessment in race walking performance: T. Yoshida et al.

Table 3. Stepwise multiple regression analysis for selected variable and best performance in the $5 \mathrm{~km}$ race walking

\begin{tabular}{clclc}
\hline $\begin{array}{c}\text { Step } \\
\text { number }\end{array}$ & Variables & $\begin{array}{c}\text { Multiple } \\
R^{2}\end{array}$ & delta $R^{2}$ & $\begin{array}{c}\text { Simple } \\
\text { correlation }\end{array}$ \\
\hline 1 & $\mathrm{~V}-\mathrm{OBLA}$ & 0.8865 & $\mathrm{P}<0.001$ & 0.94 \\
2 & $\mathrm{VO}_{2} \max$ & 0.9698 & $\mathrm{P}<0.05$ & 0.73 \\
3 & $\mathrm{~V}-\mathrm{LT}$ & 0.9797 & $\mathrm{~ns}$ & 0.85 \\
\hline
\end{tabular}

Figure 3 indicates the relationship between the measured race pace for $5 \mathrm{~km}$ race walking and the predicted race pace by the multiple regression equation as mentioned above. The slope and intercept for the regression line did not differ significantly from the identity of line $(Y=X)$.

\section{Discussion}

The major finding of this study was that blood lactate variables such as V-OBLA and V-LT explained a large portion of variance among the race pace on a $5 \mathrm{~km}$ walking performance. As expected, a simple correlation of V-OBLA with the race pace on a $5 \mathrm{~km}$ walking performance is the highest value $(\mathrm{r}=0.94, \mathrm{P}<0.001)$ and the second one is V-LT $(r=0.85, \mathrm{P}<0.01)$. Such a high relationship between lactate variables and race pace on performance have been reported in male runners and race walkers ${ }^{1-6}$. In particular, the present result agrees with the data of Hagberg and Coyle who found a similar correlation between V-LT and a $20 \mathrm{~km}$ race walking pace in male walkers $(r=0.94$; $\mathrm{P}<0.005)^{3}$. The high relationship of blood lactate variables to performance in walkers suggests that success in race walking can be determined by performance at the highest walking velocity attained without accumulation of blood lactate. This is partly explained on the basis that endurance training results in decreased muscle lactate and blood lactate levels during submaximal exercise ${ }^{10}$.

The correlation between $\mathrm{VO}_{2}$ max and the race pace on a $5 \mathrm{~km}$ walking performance in the present study was moderately significant $(r=0.74 ; P<0.05)$ compared with the correlations between blood lactate variables and performance. This relationship obtained in the present study coincided with the data of Hagberg and Coyle who described the moderate correlation $(\mathrm{r}=0.62, \mathrm{P}>0.05)$ in male race walkers ${ }^{3}$. In the literatures it is documented that endurance performance is more highly correlated with lactate variables than $\mathrm{VO}_{2}$ max $^{\|}$. This might be explained partially on the basis that the muscle respiratory capacity is correlated with blood lactate variables such as LT and/or OBLA more strongly than with $\mathrm{VO}_{2}$ max. It is suggested that $\mathrm{VO}_{2}$ max would not solely be a determinant parameter and that other variables would also contribute to race walking success.

It is interesting to note that the correlation between walking economy and race pace on a $5 \mathrm{~km}$ walking performance was not significant, although $\mathrm{r}$-value was -0.64 . The present result is in contrast to the data of Hagberg and Coyle who reported that walking economy was significantly related to the $20 \mathrm{~km}$ race pace in male walkers $(\mathrm{r}=-0.89 ; \mathrm{P}<0.001)^{3}$. It is documented that the submaximal running economy is

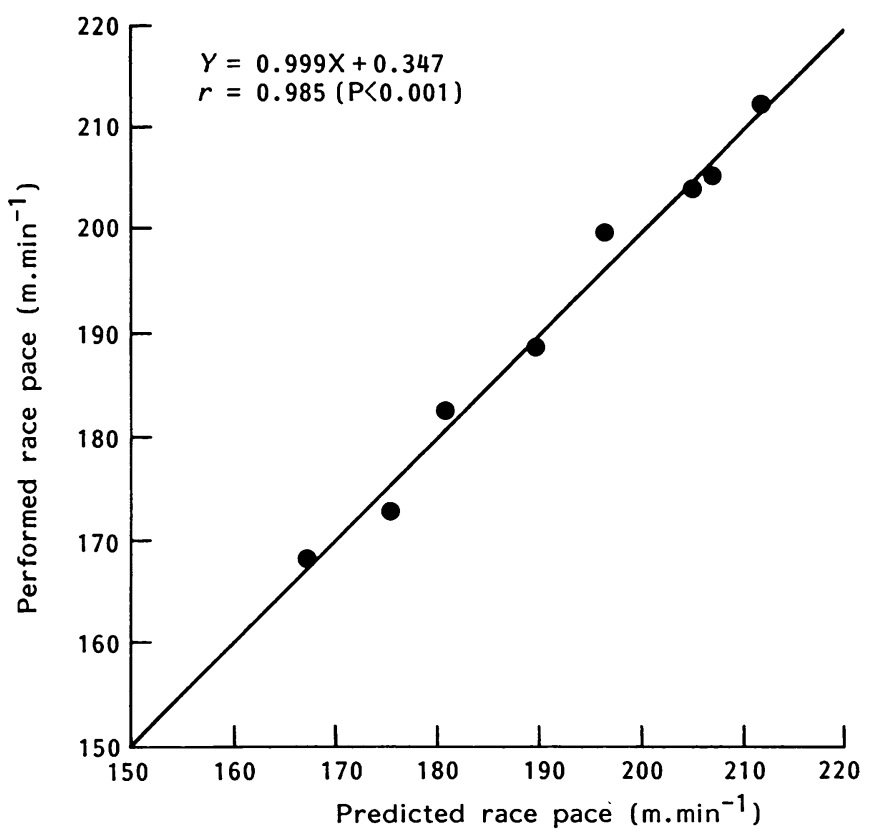

Figure 3. The relationship between actual performed race pace on a $5 \mathrm{~km}$ walking performance and the predicted race pace by multiple regression equation

related closely to performance with homogeneous runner in performance, but the correlation is relatively lower when the subjects are heterogeneous in performance ${ }^{3,13-15}$. Since the present subjects were fairly heterogeneous in terms of race walking performance (Table 1), this would be the case. Furthermore, the decrement of $\mathrm{VO}_{2}$ at standardized treadmill walking must indicate a lowered biochemical energy production.

Since a simple correlation between V-OBLA and performance in race walking accounts for a large portion $\left(R^{2}=88.6\right.$ per cent) of common variance, and the second contributor is V-LT $\left(R^{2}=72.8\right.$ per cent), these facts suggest that blood lactate variables must contribute to race walking success. Applying stepwise multiple linear regression analysis, it should be pointed out that the combination of $\mathrm{V}-\mathrm{OBLA}$ and $\mathrm{VO}_{2}$ max as independent variables accounts for the greatest amounts of total variance ( 97 per cent). Unfortunately, multiple $R$ did not increase significantly by adding variables of V-LT as independent variance, although VLT is the second contributor. Probably due to the similarity of physiological meaning for V-LT and V$\mathrm{OBLA}^{16}$, the contribution of V-LT would be rejected to predict the performance by the STEPWISE procedure.

In summary, the walking performance could be better accounted mainly for V-OBLA and when the determinants of $\mathrm{V}$-OBLA and $\mathrm{VO}_{2 \max }$ are combined as independent variables the performance was accounted for the greatest amounts of total variance ( 97 per cent).

\section{References}

1 Allen, W.K., Seals, D.R., Hurley, B., Ehsani, A.A. and Hagberg, J.M. Lactate threshold and distance running performance in young and older endurance athletes J Appl Physiol 1985, 58, 1281-1284

2 Farrell, P.A., Wilmore, J.H, Coyle, E.F., Billing, J.E. and Costill, D.L. Plasma lactate accumulation and distance running Med Sci Sports Exerc 1979, 11, 338-344 
3 Hagberg, J.M. and Coyle, E.F. Physiological determinants of endurance performance as studied in competitive racewalkers Med Sci Sports Exerc 1983, 15, 287-289

4 Kumagai, S., Tanaka, K., Matsuura, Y., Matsuzaka, A., Hirakoba, K. and Asano, K. Relationships of anaerobic threshold and the onset of blood lactate accumulation with endurance performance Eur I Appl Physiol 1983, 52, 51-56

6 Williams, C. and Nute, M.L. Some physiological demands of a half-marathon race on recreational runners Brit I Sports Med 1983, 17, 152-161

7 Foster, H.V., Dempsey, J.A., Thomson, J., Vidruk, E. and Dopico, G.A. Estimation of arterial $\mathrm{PO}_{2}, \mathrm{PCO}_{2}, \mathrm{pH}$ and lactate from arterialized venous blood I Appl Physiol 1972, 32, 134-137

8 Yoshida, T. Current topics and concepts of lactate and gas exchange thresholds J Human Ergol 1987, 16, 103-121

9 Beaver, W.L., Wasserman, K. and Whipp, B.J. Improved detection of the lactate threshold during exer- cise using a log-log transformation J Appl Physiol 1985, 59, 1936-1940

10 Holloszy, I.O., Rennie, M.I., Hickson, R.C., Conlee, R.K. and Hagberg, J.M. Physiological consequences of the biochemical adaptations to endurance exercise $A n n$ NY Acad Sci 1977, 301, 440-450

11 Jacobs, I. Blood lactate. Implications for training and sports performance. Sports Med. 1986, 3, 10-25

12 Ivy, J.L., Withers, R.T., Van Handel, P.J., Elger, D.H. and Costill, D.L. Muscle respiratory capacity and fiber types as determinants of the lactate threshold I Appl Physiol 1980, 48, 523-527

13 Conley, D.C. and Krahenbuhl, G.S. Running economy and distance running performance in highly trained athletes Med Sci Sports Exerc 1980, 12, 357-360

14 Conley, D.L., Krahenbuhl, G.S., Burkett, L.M. and Millar, A.L. Physiological correlates of female road racing performance Res Quart Exer Sport 1981, 52, 441-448

15 Costill, D.L., Thomason, H. and Roberts, E.L. Fractional utilization of aerobic capacity during distance running Med Sci Sports 1973, 5, 248-252 